\title{
Impact on Readmission Reduction Among Heart Failure Patients Using Digital Health Monitoring: Feasibility and Adoptability Study
}

Christopher Park, BA; Emamuzo Otobo, MPH, MD; Jennifer Ullman, NP; Jason Rogers, BA; Farah Fasihuddin, MPH; Shashank Garg, MS; Sarthak Kakkar, MS; Marni Goldstein, MPH; Sai Vishudhi Chandrasekhar; Sean Pinney, MD; Ashish Atreja, MPH, MD

Icahn School of Medicine at Mount Sinai, New York, NY, United States

Corresponding Author:

Ashish Atreja, MPH, MD

Icahn School of Medicine at Mount Sinai

1 Gustave L Levy Pl

New York, NY, 10029

United States

Phone: 12122418100

Email: ashish.atreja@mssm.edu

\section{Abstract}

Background: Heart failure (HF) is a condition that affects approximately 6.2 million people in the United States and has a 5 -year mortality rate of approximately $42 \%$. With the prevalence expected to exceed 8 million cases by 2030, projections estimate that total annual HF costs will increase to nearly US $\$ 70$ billion. Recently, the advent of remote monitoring technology has significantly broadened the scope of the physician's reach in chronic disease management.

Objective: The goal of our program, named the Heart Health Program, was to examine the feasibility of using digital health monitoring in real-world home settings, ascertain patient adoption, and evaluate impact on 30-day readmission rate.

Methods: A digital medicine software platform developed at Mount Sinai Health System, called RxUniverse, was used to prescribe a digital care pathway including the HealthPROMISE digital therapeutic and iHealth mobile apps to patients' personal smartphones. Vital sign data, including blood pressure (BP) and weight, were collected through an ambulatory remote monitoring system that comprised a mobile app and complementary consumer-grade Bluetooth-connected smart devices (BP cuff and digital scale) that send data to the provider care teams. Care teams were alerted via a Web-based dashboard of abnormal patient BP and weight change readings, and further action was taken at the clinicians' discretion. We used statistical analyses to determine risk factors associated with 30-day all-cause readmission.

Results: Overall, the Heart Health Program included 58 patients admitted to the Mount Sinai Hospital for HF. The 30-day hospital readmission rate was $10 \%(6 / 58)$, compared with the national readmission rates of approximately $25 \%$ and the Mount Sinai Hospital's average of approximately $23 \%$. Single marital status $(P=.06)$ and history of percutaneous coronary intervention $(P=.08)$ were associated with readmission. Readmitted patients were also less likely to have been previously prescribed angiotensin-converting enzyme inhibitors or angiotensin II receptor blockers $(P=.02)$. Notably, readmitted patients utilized the $\mathrm{BP}$ and weight monitors less than nonreadmitted patients, and patients aged younger than 70 years used the monitors more frequently on average than those aged over 70 years, though these trends did not reach statistical significance. The percentage of the 58 patients using the monitors at least once dropped from $83 \%(42 / 58)$ in the first week after discharge to $46 \%$ (23/58) in the fourth week.

Conclusions: Given the increasing burden of HF, there is a need for an effective and sustainable remote monitoring system for HF patients following hospital discharge. We identified clinical and social factors as well as remote monitoring usage trends that identify targetable patient populations that could benefit most from integration of daily remote monitoring. In addition, we demonstrated that interventions driven by real-time vital sign data may greatly aid in reducing hospital readmissions and costs while improving patient outcomes.

(JMIR Med Inform 2019;7(4):e13353) doi: $\underline{10.2196 / 13353}$ 


\section{KEYWORDS}

heart failure; blood pressure; body weight; mHealth; remote consultation; patient care management; patient readmission; cell phone; mobile phone; blood pressure monitors; mobile apps

\section{Introduction}

\section{Background}

Heart failure (HF) currently affects about 6.2 million people in the United States and has an approximate 5-year mortality rate of $42 \%$ [1,2]. With the incidence rate projected to rise by $46 \%$ to exceed 8 million cases by 2030, HF is an increasing public health concern [2]. Furthermore, although admission rates for HF have declined over the past two decades [3], readmission rates have not [1,4]; Centers for Medicare and Medicaid Services (CMS) data suggest that about $25 \%$ of $\mathrm{HF}$ patients are readmitted within 30 days after initial hospitalization, and 35\% of these readmissions are because of HF [5]. About half of discharged HF patients are readmitted within 6 months post discharge. In 2012, the HF cost burden was estimated to be US $\$ 30$ billion, and projections show that by 2030 , total HF costs will increase $125 \%$ from 2012 to nearly US $\$ 70$ billion, which averages to US \$244 for each US adult [2].

Numerous studies have been aimed at understanding the greatest risk factors for HF readmission, and results are widely varied [6-13]. The American Heart Association reports that old age, African-American race, hypertension, diabetes mellitus (DM), and low socioeconomic status were associated with higher incidence of HF [1,2]. Other reported factors include nonclinical factors such as single marital status and Medicare/Medicaid status, and clinical factors such as renal failure, chronic obstructive pulmonary disease (COPD), and history of drug use $[8,9,11,14-22]$. Many studies have sought to build models that use these factors to predict readmission for HF patients $[14,16,17,22-26]$. However, these prediction schemes have struggled to universally reduce readmission rates for HF patients because of lack of evidence and inconsistencies in determining relevant factors $[1,22,26]$.

Owing to the advent of remote monitoring technology, recent attempts to reduce readmission rates have begun to integrate modes by which physicians directly track their patients' health statuses [27,28]. In addition to promoting a steadier communication between physician and patient, such protocols actively encourage patient participation in their own health, which has been shown to facilitate informed decision making and increase health literacy [29-31]. Studies utilizing remote monitoring for HF patients have shown varying but promising results; however, many of the reported solutions were done in research settings and required significant staff resources and costs associated with integration of telemonitoring $[28,29,32,33]$.

\section{Objectives}

In our quality improvement (QI) initiative, named the Heart Health Program, we developed a time-efficient and relatively cost-effective remote monitoring mobile device platform, prescribed from electronic health record (EHR)-connected platform, which helped to reduce hospital readmissions among HF patients. In addition to assessing readmission rates, we aimed to identify and analyze monitor usage and adherence trends in real-world home settings to inform future interventions to be conducted on larger scales.

\section{Methods}

\section{Participants}

The program included 60 patients who were admitted to the Mount Sinai Hospital for a diagnosis of acute HF. Under an approved QI protocol, eligible patients were approached around 2 days before discharge, and interested patients were enrolled in the Heart Health Program, a digital health monitoring initiative.

\section{Intervention Protocol}

Our digital care pathway "solution toolkit" consisted of apps (HealthPROMISE digital therapeutic and iHealth mobile apps) that were prescribed using RxUniverse Digital Medicine platform (Rx.Health, Inc). RxUniverse is an EHR-integrated platform that allows digital prescription of automated care pathways including apps, digital therapeutics, education, and reminders directly to patients. This platform has been previously shown to have high usability and patient activation rate [34]. Patients were provided with HF education content, SMS or text reminders, and the ability to track their patient-reported outcomes (PROs) via preselected symptom checkboxes on HealthPROMISE digital therapeutic. In addition, each patient was provided with a complementary, consumer-grade Bluetooth-connected weight scale and blood pressure (BP) monitor that connected to the iHealth app installed on their own smartphone. Patients were instructed to measure their weight and BP each day. The total cost of equipment for each patient was US $\$ 110$, paid for by the institution (Figure 1).

Electronic PRO and Bluetooth scale and BP monitor data were sent to a Web-based dashboard (Figure 2), which was monitored daily by a patient health coordinator (coauthor, EO) who worked with the clinical team to assess symptoms and respond as needed. The clinical team comprised the nurse manager for the patient floor and a cardiologist. Any critical red-flag values, for example, a greater than 2-pound weight gain within 24 hours or greater than 5-pound weight gain within a week automatically alerted the physician and prompted the patient to seek medical attention. The alerted physician could then elect to have the patient contacted to set up an appointment with the cardiologist. Physicians were also able to contact patients based on individual judgment of changes in $\mathrm{BP}$ or weight. This pipeline is illustrated in Figure 3. This program was exempted by the institutional review board and classified as a QI study by the Department of Medicine's QI Board. 
Figure 1. Digital care pathway "solution toolkit" for heart failure patients' remote monitoring.
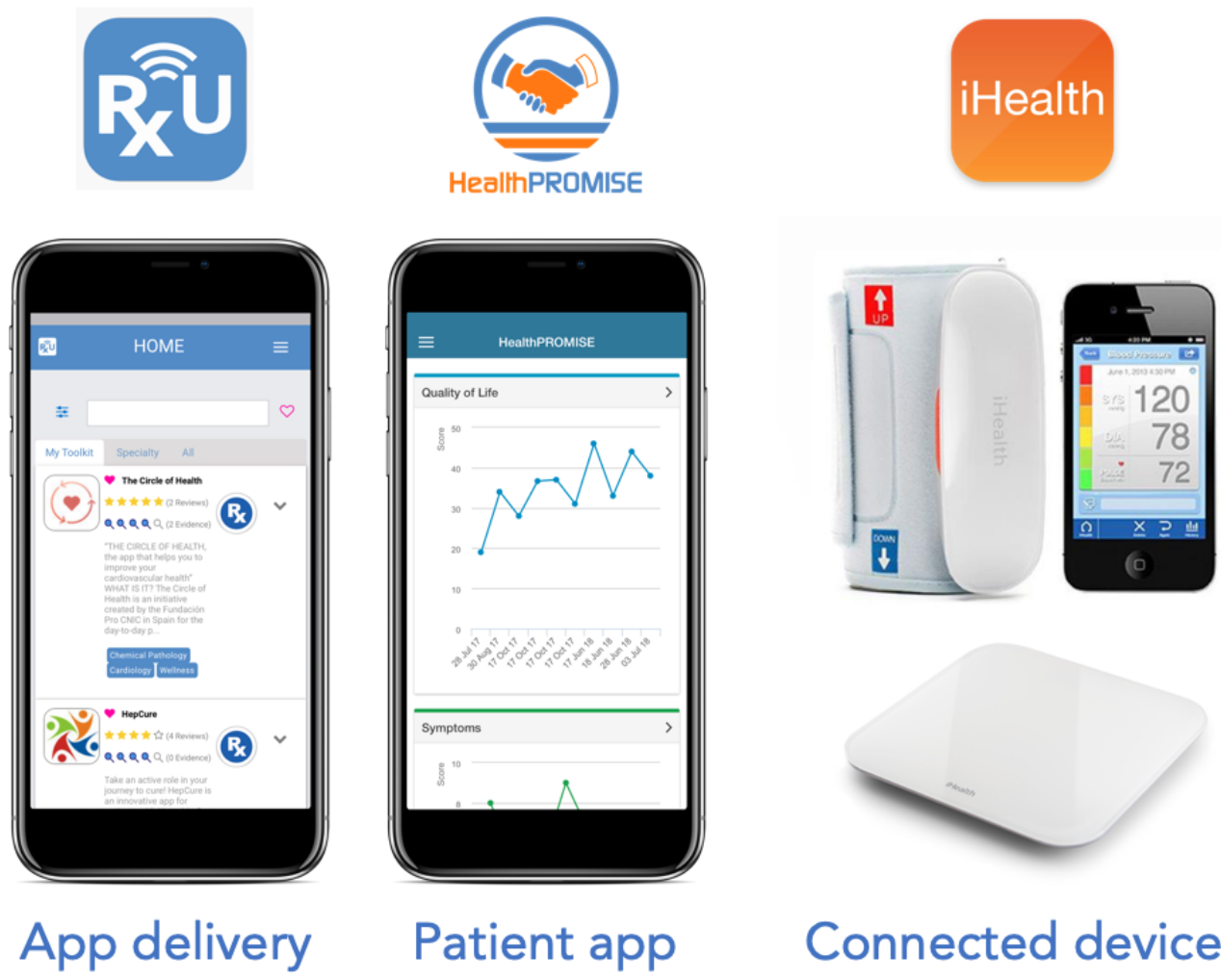

Figure 2. Screenshot of the electronic patient-reported outcomes data dashboard.

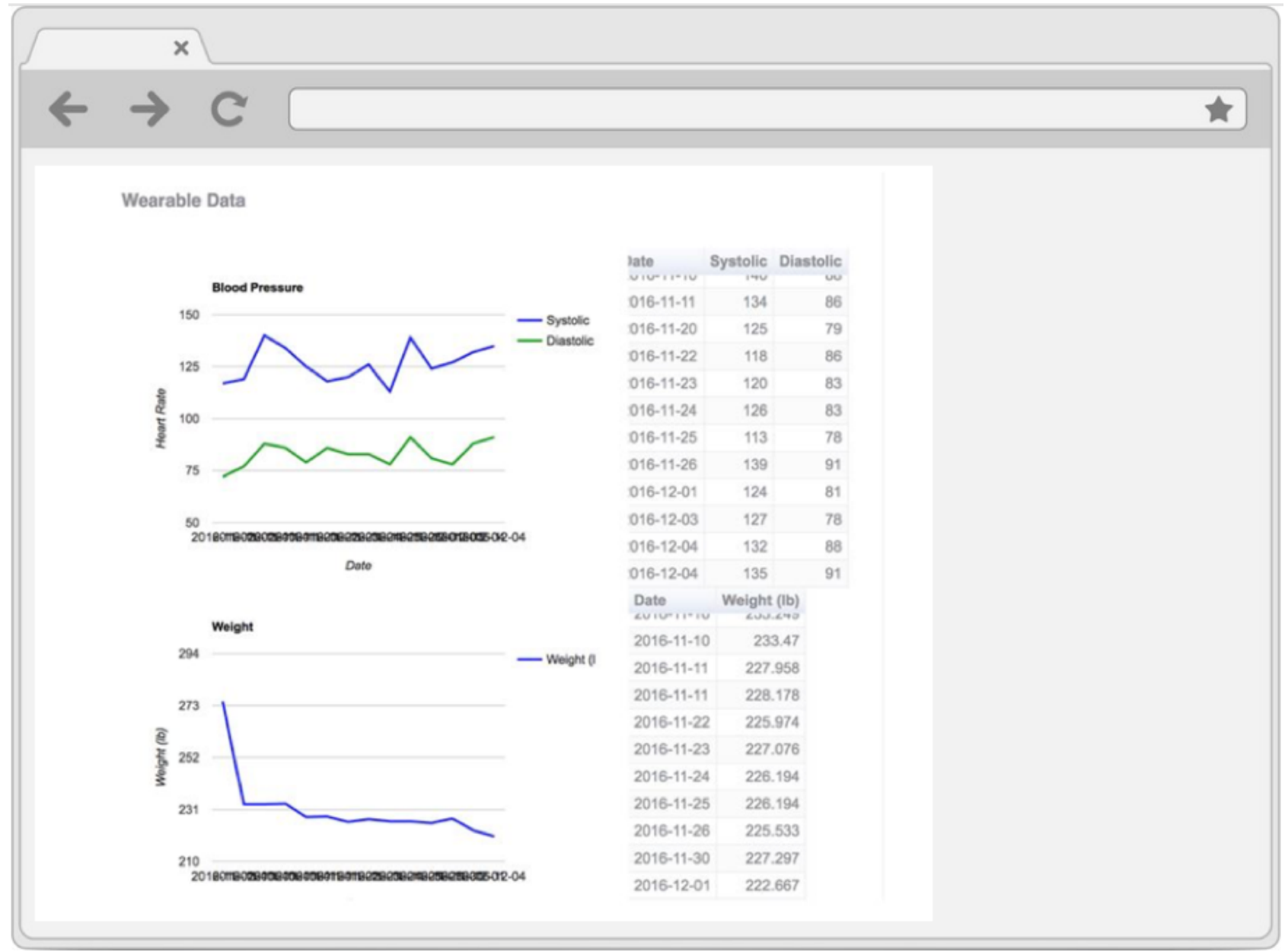


Figure 3. Intervention protocol pipeline and roles. EHR: electronic heath record.

Set up appointment with cardiologist

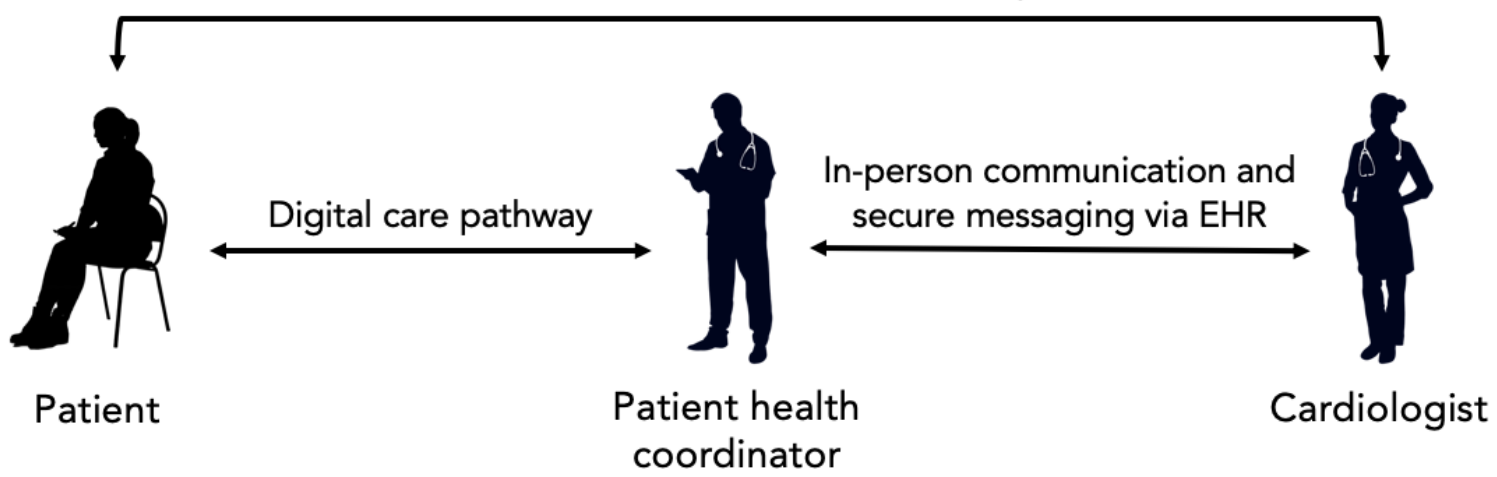

\section{Dependent Variables}

The primary outcome measured was 30-day all-cause readmission. In addition, usage of the monitors was defined as the number of times patients would use the weight and BP monitors per week following discharge. Usage for each monitor was calculated separately.

\section{Covariates}

All patient data were pulled from EHRs, HealthPROMISE digital therapeutic, and Bluetooth-connected devices. Demographic variables included age, sex, race, and marital status. Clinical and social factors included insurance status; previous percutaneous coronary intervention (PCI); drug abuse; prescription of angiotensin-converting enzyme inhibitor (ACEI) or angiotensin II receptor blocker (ARB); prior HF; prior hospitalization within the last 12 or 6 months; and diagnoses of systolic HF, atrial fibrillation, COPD, depression, anxiety, cancer, coronary artery disease, HIV, DM, and anemia. Factors were selected based on a comprehensive literature search of factors correlated with HF readmission.

\section{Analysis}

Readmission rates were compared with the reported Mount Sinai Hospital's standard HF all-cause 30-day readmission rate as well as the national readmission rate. Patient characteristics were compared between the readmission and nonreadmission group using $t$ tests and Fischer exact tests as appropriate. Finally, BP and weight monitor usage trends were qualitatively and quantitatively analyzed based on weekly usage percentage. All statistical tests are reported with the absolute $P$ values.

\section{Results}

\section{Patient Characteristics}

A total of 60 patients were enrolled in the Heart Health demonstration program. Two patients dropped out because of personal reasons. Of the remaining 58 patients in the program, $33 \%(n=19)$ were female and $67 \%(n=39)$ were male, with a median age of 62 years (Table 1). Of the 58 patients, 57 were on Medicare or Medicaid. A majority of patients had been hospitalized in the prior 12 months before discharge $(60 \%$, $\mathrm{n}=36)$ and were single $(55 \%, \mathrm{n}=32)$.

\section{Readmission Statistics}

Overall, there were 6 hospital readmissions $(10 \%, 6 / 58)$ after 30 days, compared with the national 30-day readmission rate of $25 \%$, which denotes a significant decrease $(P=.06)$, and Mount Sinai Hospital's readmission rate of $23 \%$. As shown in Table 1, readmission was associated with single status $(P=.06)$, a previous PCI $(P=.08)$, and no prescription of ACEI or ARB $(P=.02)$. 
Table 1. Patient characteristics for 30-day readmitted and nonreadmitted patients.

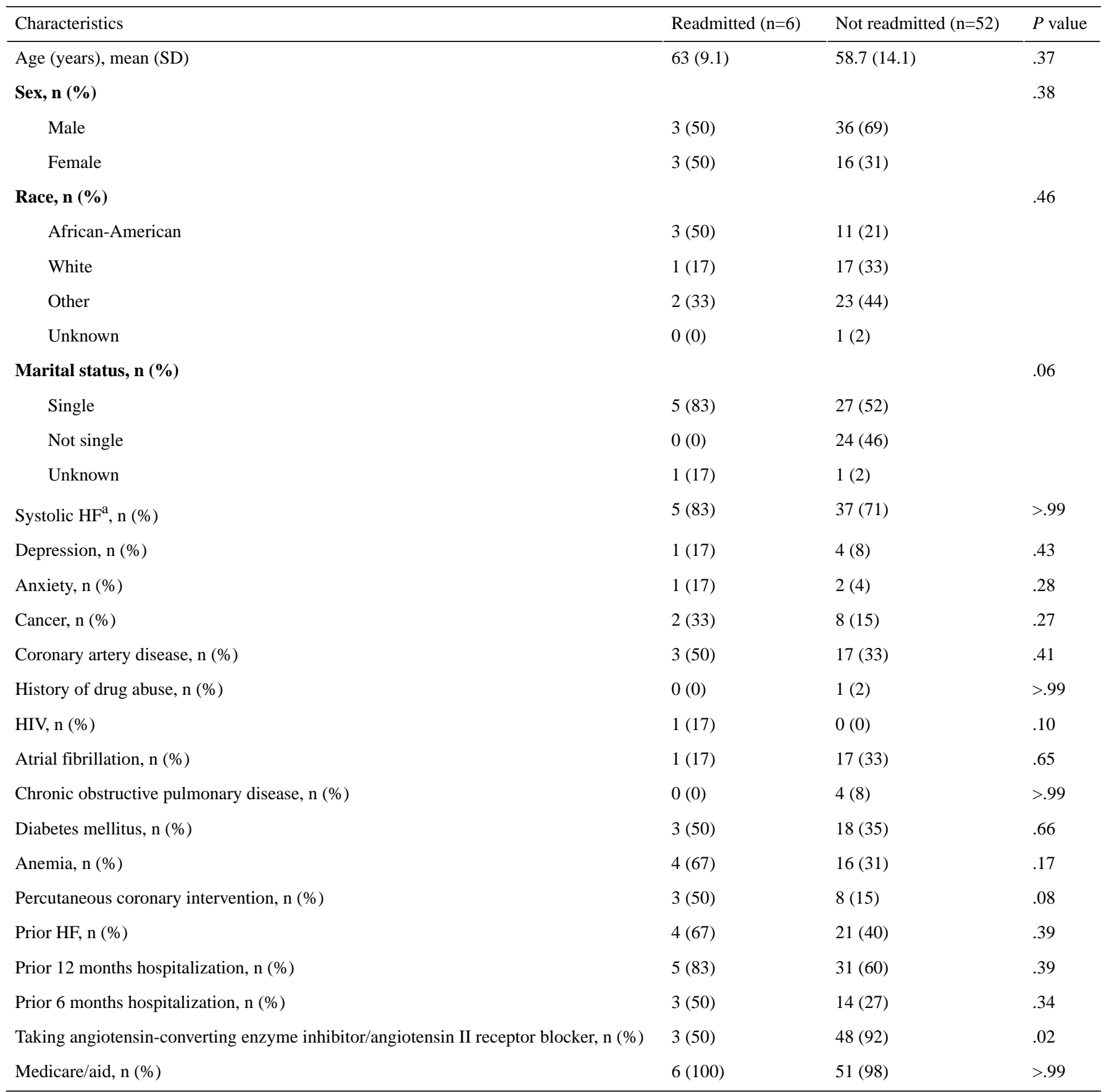

${ }^{\mathrm{a}} \mathrm{HF}$ : heart failure.

\section{Device Usage}

The percentage of the total 58 patients using the monitors at least once dropped steadily from $83 \%(n=48)$ in the first week after discharge to $46 \%(n=27)$ in the fourth week (Figure 4; ie, in the fourth week following discharge, $46 \%$ of the original 58 patients, or 27 patients, were still using the BP monitor at least once). The percentage of patients using the monitors at least five times per week dropped from around $50 \%(n=29)$ to $30 \%$ $(\mathrm{n}=17)$ by the fourth week. Patients, on average, used the BP monitor more often than the weight scale. Device usage was not correlated with any patient characteristic or demographic factor.

Readmitted patients utilized the BP and weight monitors less frequently than nonreadmitted patients, and patients aged less than 70 years used the monitors more frequently on average than those aged more than 70 years. Furthermore, patients were more likely to use the monitors on weekdays compared with weekends. These trends, however, did not reach statistical significance. 
Figure 4. Absolute percentage of the total 58 patients with at least 1 or at least 5 blood pressure (BP) and weight checks each week following discharge.

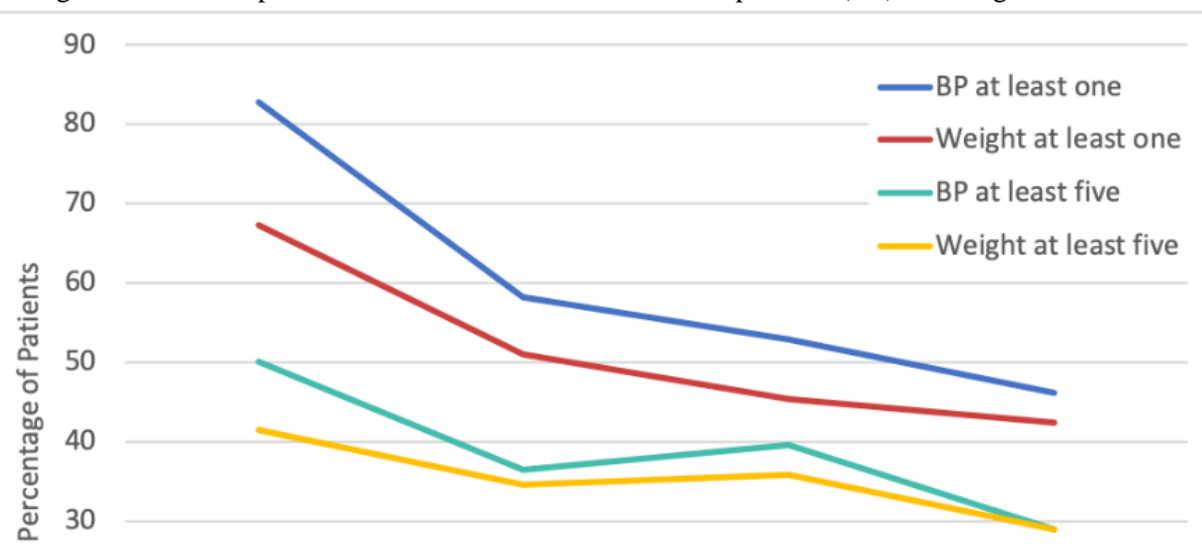

\section{Discussion}

\section{Overview}

Readmission rates for HF patients have not decreased in the last few decades, and in fact, have risen, likely because of the decreased mortality and subsequent increased prevalence of $\mathrm{HF}$ patients [1]. Thus, strategies aimed at reducing readmissions are essential. The goal of this QI initiative was to assess feasibility (in part measured by readmission reduction and adherence rates) of using affordable digital health monitoring in real-world home settings, ascertain patient adoption trends, and evaluate impact on 30-day readmission rate as the primary outcome. We demonstrated that remote monitoring of BP and weight data via an app-based platform can be affordable, be adopted by patients irrespective of age, and reduce 30-day readmissions in real-world setting. We further identified usage trends that will be informative for future population health-wide implementations.

\section{Readmission Statistics}

Our program's readmission rate of $10 \%$ represented a significant decrease in 30-day readmission rate compared with both the Mount Sinai Hospital's rate $(23 \%)$ as well as the national rate (25\%). Readmitted patients utilized the BP and weight monitors less frequently than nonreadmitted patients, and device usage was not correlated with any patient characteristic or demographic factor. These results support the published literature on the potential role of technology-aided remote care in HF patient management [27,30-32]. However, many of the published solutions were conducted in research settings and required invasive monitor placement, significant staff resources, or expensive equipment, which may not be necessary for all $\mathrm{HF}$ patients [31,32,34,35].

We were able to integrate an intervention protocol that reduced barriers to adherence on both the physician side and patient side by developing mobile apps that automated many parts of the workflow: PROs and monitor data were sent directly to a dashboard via mobile apps, and the patient health coordinator would only need to notify the physician of suspicious readings or symptoms. In addition, the RxUniverse platform would automatically notify patients to enter their symptoms on the app and measure their weight and BP. Thus, we were able to remove the need for telemonitoring, frequent check-ins for every patient, and the hassle that many patients may face in recording daily symptom and weight readings manually.

Besides physician monitoring of patient health status, interventions such as ours may also play a greater role in facilitating patient engagement with their own health [36]. For example, in receiving a weight scale, patients can be educated that quick increases in weight may reflect fluid retention because of high salt intake, which can exacerbate the HF symptoms. In this way, patients may be educated on their own condition, which has been shown to decrease mortality, morbidity, and costs associated with the disease [36-38].

\section{Device Usage}

Decreased patient adherence to discharge protocols is one of the most prominent obstacles in HF patient management $[39,40]$. In our program, the vast majority of patients used the monitors in the week following discharge, and about half of the patients continued to measure their weight and BP at least once in the fourth week following discharge. The first week after discharge is the most vulnerable period for patients, and high engagement during that time was one of the important factors in reducing readmission rate. This drop in adherence from the first week onward may be attributable to numerous context-dependent factors, such as low motivation once patients know they are out of the "danger zone," lack of long-term nursing or social support and/or living alone, and low technological proficiency [41]. Although some of these factors were beyond the scope of our program, these data provide insight into how intervention timing may be improved. As adherence falls after the first week, perhaps a front-loaded approach to increase patient engagement (via automated SMS text messages, direct interactive voice 
response calls, telemedicine and incentives when needed, etc) rather than an evenly spaced approach would increase and have a more long-lasting effect.

It is important to note that the number of patients taking BP and weight readings at least five times per week did not fall as drastically as the number of patients taking readings at least once per week. Furthermore, the majority of patients using the monitor at least five times in week 1 after discharge were the same as those in week 4 . In other words, frequent monitor users are more likely to stay frequent users in the long run. Thus, patients that exhibit drastic decreases in monitor usage after the first week may represent a more specific targetable population.

In the past decade, remote monitoring, namely telemonitoring, has become a large field of interest in chronic disease management, and studies such as the Weight and Activity with Blood Pressure Monitoring System have described detailed protocols for such modalities [34]. In addition, studies that have implemented these monitoring solutions have showed great promise in reducing mortality and readmission [27]. However, many of the proposed workflows, in addition to the telemonitoring, require personnel-heavy intervention strategies, such as frequent phone calls and videoconferencing [27,29].

Many mobile apps have also been developed to help patients better manage HF, such as PatientConnect and HeartMapp [42]. Our app toolkit is similar to these apps in that it provides educational materials, care plans, reminders, in-app communication, and input options for PROs. In addition, our toolkit (1) integrates Bluetooth connectivity and automated updates of patient BP and weight data on the physician's dashboard and (2) implements newly developed digital care pathways that can be delivered to patients without the need for mobile app downloads (eg, via SMS text messages). In our Heart Health Program, we reduced readmission by exclusively using remotely collected BP and weight readings, significantly reducing the cost and staff burden compared with other more resource-heavy interventions [29,32]. Coupled with the development of cheaper Bluetooth monitors and more effective risk stratification of patients who need monitors, our approach may be scaled as larger health systems look to expand digital health monitoring enterprise-wide to all HF patients. The Heart Health Program is now being expanded across multiple health systems through a nationwide digital transformation network in partnership with the American College of Cardiology.

\section{Limitations}

Owing to our program being a demonstration program, our sample size was limited to 60 participants. Future research should use similar interventions on larger populations as well as different population demographics. Our sample size was also influenced by barriers to enrollment, including onboarding time, competition with other hospital initiatives and research trials, missed recruiting opportunities because of limited notice of discharge, language barriers, and smartphone ownership. Our program addressed these issues by enrolling HF patients around 2 days before expected discharge and adding a patient health coordinator to hospital rounds. Future research studies using device-dependent remote interventions on a larger scale could establish personnel with specific roles to address these issues and to maximize enrollment efficiency. Finally, consistent with real-world QI initiatives, specific physician-patient communications were not protocolized, and it was left to individual physicians to follow their best practices when patients' alerts were seen. Additional work could be done to integrate a mobile app-enabled protocol where physicians may report their communications with patients to gain more granular data.

\section{Conclusions}

Despite rigorous ongoing research, $\mathrm{HF}$ continues to contribute to increased health care costs and hospitalizations [1]. As technology advances, there is an increasing opportunity for a comprehensive, affordable, and personalized solution that can leverage existing technology to provide care to patients post discharge in real-world settings [31,43]. Recently, CMS approved reimbursement codes for remote monitoring and nonface-to-face chronic care disease management [44]. Diseases with increasing cost and health burdens such as HF could particularly benefit from such solutions. In our program, we demonstrated that interventions driven by real-time vital sign data may greatly aid in reducing hospital readmissions and costs, improving patient outcomes. Remote monitoring protocols such as ours both facilitate caregiver-patient interactions as well as engage the patient in his or her own health. Furthermore, remote monitoring programs have the potential to be scalable, especially when combined with digital medicine platforms integrated with EHRs. Future studies should seek to measure population health-wide impact on outcomes and revenue as digital health remote monitoring is expanded enterprise-wide.

\section{Acknowledgments}

This initiative is supported in part by National Institutes of Health grants (K23, NIDDK, K23DK097451-01A1: AA) and CTSA (UL1TR000067: H Sampson).

\section{Conflicts of Interest}

The RxUniverse software platform and HealthPROMISE digital therapeutic are licensed technologies from Icahn School of Medicine at Mount Sinai to Rx.Health, Inc (New York, NY). AA, SK, and JR own stock in Rx.Health and have recused themselves from data analysis. SP receives consulting fees from Abbott, CareDx, Medtronic, and Procyrion and has recused himself from data analysis.

\section{References}


1. Roger VL. Epidemiology of heart failure. Circ Res 2013 Aug 30;113(6):646-659 [FREE Full text] [doi: 10.1161/CIRCRESAHA.113.300268] [Medline: 23989710]

2. Benjamin EJ, Muntner P, Alonso A, Bittencourt MS, Callaway CW, Carson AP, American Heart Association Council on Epidemiology and Prevention Statistics Committee and Stroke Statistics Subcommittee. Heart disease and stroke statistics-2019 update: a report from the American heart association. Circulation 2019 Mar 5;139(10):e56-528. [doi: 10.1161/CIR.0000000000000659] [Medline: 30700139]

3. Chen J, Normand ST, Wang Y, Krumholz HM. National and regional trends in heart failure hospitalization and mortality rates for Medicare beneficiaries, 1998-2008. J Am Med Assoc 2011 Oct 19;306(15):1669-1678 [FREE Full text] [doi: 10.1001/jama.2011.1474] [Medline: 22009099]

4. Bueno H, Ross JS, Wang Y, Chen J, Vidán MT, Normand ST, et al. Trends in length of stay and short-term outcomes among Medicare patients hospitalized for heart failure, 1993-2006. J Am Med Assoc 2010 Jun 2;303(21):2141-2147 [FREE Full text] [doi: 10.1001/jama.2010.748] [Medline: 20516414]

5. Dharmarajan K, Hsieh AF, Lin Z, Bueno H, Ross JS, Horwitz LI, et al. Diagnoses and timing of 30-day readmissions after hospitalization for heart failure, acute myocardial infarction, or pneumonia. J Am Med Assoc 2013 Jan 23;309(4):355-363 [FREE Full text] [doi: 10.1001/jama.2012.216476] [Medline: 23340637]

6. Aizawa H, Imai S, Fushimi K. Factors associated with 30-day readmission of patients with heart failure from a Japanese administrative database. BMC Cardiovasc Disord 2015 Oct 24;15:134 [FREE Full text] [doi: 10.1186/s 12872-015-0127-9] [Medline: 26497394]

7. Anderson MA, Levsen J, Dusio ME, Bryant PJ, Brown SM, Burr CM, et al. Evidenced-based factors in readmission of patients with heart failure. J Nurs Care Qual 2006;21(2):160-167. [Medline: 16540785]

8. Arora S, Lahewala S, Hassan Virk HU, Setareh-Shenas S, Patel P, Kumar V, et al. Etiologies, trends, and predictors of 30-day readmissions in patients with diastolic heart failure. Am J Cardiol 2017 Aug 15;120(4):616-624. [doi:

10.1016/j.amjcard.2017.05.028] [Medline: 28648393]

9. Chamberlain RS, Sond J, Mahendraraj K, Lau CS, Siracuse BL. Determining 30-day readmission risk for heart failure patients: the Readmission After Heart Failure scale. Int J Gen Med 2018;11:127-141 [FREE Full text] [doi: 10.2147/IJGM.S150676] [Medline: 29670391]

10. Kaneko H, Suzuki S, Goto M, Arita T, Yuzawa Y, Yagi N, et al. Incidence and predictors of rehospitalization of acute heart failure patients. Int Heart J 2015;56(2):219-225 [FREE Full text] [doi: 10.1536/ihj.14-290] [Medline: 25740584]

11. Mirkin KA, Enomoto LM, Caputo GM, Hollenbeak CS. Risk factors for 30-day readmission in patients with congestive heart failure. Heart Lung 2017;46(5):357-362. [doi: 10.1016/j.hrtlng.2017.06.005] [Medline: 28801110]

12. Ponce SG, Norris J, Dodendorf D, Martinez M, Cox B, Laskey W. Impact of ethnicity, sex, and socio-economic status on the risk for heart failure readmission: the importance of context. Ethn Dis 2018;28(2):99-104 [FREE Full text] [doi: 10.18865/ed.28.2.99] [Medline: 29725194]

13. Sherer AP, Crane PB, Abel WM, Efird J. Predicting heart failure readmissions. J Cardiovasc Nurs 2016;31(2):114-120. [doi: 10.1097/JCN.0000000000000225] [Medline: 25513988]

14. Felker GM, Leimberger JD, Califf RM, Cuffe MS, Massie BM, Adams KF, et al. Risk stratification after hospitalization for decompensated heart failure. J Card Fail 2004 Dec;10(6):460-466. [doi: 10.1016/j.cardfail.2004.02.011] [Medline: 15599835]

15. Chin MH, Goldman L. Correlates of early hospital readmission or death in patients with congestive heart failure. Am $\mathbf{J}$ Cardiol 1997 Jun 15;79(12):1640-1644. [doi: 10.1016/s0002-9149(97)00214-2] [Medline: 9202355]

16. Philbin EF, DiSalvo TG. Prediction of hospital readmission for heart failure: development of a simple risk score based on administrative data. J Am Coll Cardiol 1999 May;33(6):1560-1566 [FREE Full text] [doi: 10.1016/s0735-1097(99)00059-5] [Medline: 10334424]

17. Krumholz HM, Chen YT, Wang Y, Vaccarino V, Radford MJ, Horwitz RI. Predictors of readmission among elderly survivors of admission with heart failure. Am Heart J 2000 Jan;139(1 Pt 1):72-77. [doi: 10.1016/s0002-8703(00)90311-9] [Medline: 10618565]

18. Amarasingham R, Moore BJ, Tabak YP, Drazner MH, Clark CA, Zhang S, et al. An automated model to identify heart failure patients at risk for 30-day readmission or death using electronic medical record data. Med Care 2010 Nov;48(11):981-988. [doi: 10.1097/MLR.0b013e3181ef60d9] [Medline: 20940649]

19. Bradford C, Shah BM, Shane P, Wachi N, Sahota K. Patient and clinical characteristics that heighten risk for heart failure readmission. Res Social Adm Pharm 2017 Nov;13(6):1070-1081. [doi: 10.1016/j.sapharm.2016.11.002] [Medline: 27888091]

20. Korda RJ, Du W, Day C, Page K, Macdonald PS, Banks E. Variation in readmission and mortality following hospitalisation with a diagnosis of heart failure: prospective cohort study using linked data. BMC Health Serv Res 2017 Mar 21;17(1):220 [FREE Full text] [doi: 10.1186/s12913-017-2152-0] [Medline: 28320381]

21. Ketterer MW, Draus C, McCord J, Mossallam U, Hudson M. Behavioral factors and hospital admissions/readmissions in patients with CHF. Psychosomatics 2014;55(1):45-50. [doi: 10.1016/j.psym.2013.06.019] [Medline: 24016384]

22. Betihavas V, Davidson PM, Newton PJ, Frost SA, Macdonald PS, Stewart S. What are the factors in risk prediction models for rehospitalisation for adults with chronic heart failure? Aust Crit Care 2012 Feb;25(1):31-40. [doi:

10.1016/j.aucc.2011.07.004] [Medline: 21889893] 
23. Eapen ZJ, Liang L, Fonarow GC, Heidenreich PA, Curtis LH, Peterson ED, et al. Validated, electronic health record deployable prediction models for assessing patient risk of 30-day rehospitalization and mortality in older heart failure patients. JACC Heart Fail 2013 Jun;1(3):245-251 [FREE Full text] [doi: 10.1016/j.jchf.2013.01.008] [Medline: 24621877]

24. Formiga F, Masip J, Chivite D, Corbella X. Applicability of the heart failure Readmission Risk score: a first European study. Int J Cardiol 2017 Jun 1;236:304-309. [doi: 10.1016/j.ijcard.2017.02.024] [Medline: 28407978]

25. Hernandez MB, Schwartz RS, Asher CR, Navas EV, Totfalusi V, Buitrago I, et al. Predictors of 30-day readmission in patients hospitalized with decompensated heart failure. Clin Cardiol 2013 Sep;36(9):542-547 [FREE Full text] [doi: 10.1002/clc.22180] [Medline: 23929763]

26. Ross JS, Mulvey GK, Stauffer B, Patlolla V, Bernheim SM, Keenan PS, et al. Statistical models and patient predictors of readmission for heart failure: a systematic review. Arch Intern Med 2008 Jul 14;168(13):1371-1386. [doi: 10.1001/archinte.168.13.1371] [Medline: 18625917]

27. Conway A, Inglis SC, Clark RA. Effective technologies for noninvasive remote monitoring in heart failure. Telemed J E Health 2014 Jun;20(6):531-538 [FREE Full text] [doi: 10.1089/tmj.2013.0267] [Medline: 24731212]

28. Zai AH, Ronquillo JG, Nieves R, Chueh HC, Kvedar JC, Jethwani K. Assessing hospital readmission risk factors in heart failure patients enrolled in a telemonitoring program. Int J Telemed Appl 2013;2013:305819 [FREE Full text] [doi: 10.1155/2013/305819] [Medline: 23710170]

29. Rosen D, McCall JD, Primack BA. Telehealth protocol to prevent readmission among high-risk patients with congestive heart failure. Am J Med 2017 Nov;130(11):1326-1330. [doi: 10.1016/j.amjmed.2017.07.007] [Medline: 28756266]

30. Currie K, Strachan PH, Spaling M, Harkness K, Barber D, Clark AM. The importance of interactions between patients and healthcare professionals for heart failure self-care: a systematic review of qualitative research into patient perspectives. Eur J Cardiovasc Nurs 2015 Dec;14(6):525-535. [doi: 10.1177/1474515114547648] [Medline: 25139468]

31. Kvedar J, Coye MJ, Everett W. Connected health: a review of technologies and strategies to improve patient care with telemedicine and telehealth. Health Aff (Millwood) 2014 Feb;33(2):194-199. [doi: 10.1377/hlthaff.2013.0992] [Medline: 24493760]

32. Chaudhry SI, Phillips CO, Stewart SS, Riegel B, Mattera JA, Jerant AF, et al. Telemonitoring for patients with chronic heart failure: a systematic review. J Card Fail 2007 Feb;13(1):56-62 [FREE Full text] [doi: 10.1016/j.cardfail.2006.09.001] [Medline: 17339004]

33. Bashi N, Karunanithi M, Fatehi F, Ding H, Walters D. Remote monitoring of patients with heart failure: an overview of systematic reviews. J Med Internet Res 2017 Jan 20;19(1):e18 [FREE Full text] [doi: 10.2196/jmir.6571] [Medline: $\underline{28108430]}$

34. Suh MK, Chen CA, Woodbridge J, Tu MK, Kim JI, Nahapetian A, et al. A remote patient monitoring system for congestive heart failure. J Med Syst 2011 Oct;35(5):1165-1179 [FREE Full text] [doi: 10.1007/s10916-011-9733-y] [Medline: 21611788]

35. Guidi G, Pollonini L, Dacso CC, Iadanza E. A multi-layer monitoring system for clinical management of congestive heart failure. BMC Med Inform Decis Mak 2015;15 Suppl 3:S5 [FREE Full text] [doi: 10.1186/1472-6947-15-S3-S5] [Medline: 26391638]

36. Cajita MI, Cajita TR, Han HR. Health literacy and heart failure: a systematic review. J Cardiovasc Nurs 2016;31(2):121-130 [FREE Full text] [doi: 10.1097/JCN.0000000000000229] [Medline: 25569150]

37. Haun JN, Patel NR, French DD, Campbell RR, Bradham DD, Lapcevic WA. Association between health literacy and medical care costs in an integrated healthcare system: a regional population based study. BMC Health Serv Res 2015 Jun 27;15:249 [FREE Full text] [doi: 10.1186/s12913-015-0887-z] [Medline: 26113118]

38. McNaughton CD, Cawthon C, Kripalani S, Liu D, Storrow AB, Roumie CL. Health literacy and mortality: a cohort study of patients hospitalized for acute heart failure. J Am Heart Assoc 2015 Apr 29;4(5) [FREE Full text] [doi: 10.1161/JAHA.115.001799] [Medline: 25926328]

39. Ding H, Jayasena R, Maiorana A, Dowling A, Chen SH, Karunanithi M, et al. Innovative Telemonitoring Enhanced Care Programme for Chronic Heart Failure (ITEC-CHF) to improve guideline compliance and collaborative care: protocol of a multicentre randomised controlled trial. BMJ Open 2017 Oct 8;7(10):e017550 [FREE Full text] [doi:

10.1136/bmjopen-2017-017550] [Medline: 28993389]

40. Stut W, Deighan C, Cleland JG, Jaarsma T. Adherence to self-care in patients with heart failure in the HeartCycle study. Patient Prefer Adherence 2015;9:1195-1206 [FREE Full text] [doi: 10.2147/PPA.S88482] [Medline: 26316725]

41. Strachan PH, Currie K, Harkness K, Spaling M, Clark AM. Context matters in heart failure self-care: a qualitative systematic review. J Card Fail 2014 Jun;20(6):448-455. [doi: 10.1016/j.cardfail.2014.03.010] [Medline: 24735549]

42. Athilingam P, Labrador MA, Remo EF, Mack L, San Juan AB, Elliott AF. Features and usability assessment of a patient-centered mobile application (HeartMapp) for self-management of heart failure. Appl Nurs Res 2016 Nov;32:156-163. [doi: 10.1016/j.apnr.2016.07.001] [Medline: 27969021]

43. Davarzani N, van Wijk SS, Maeder MT, Rickenbacher P, Smirnov E, Karel J, TIME-CHF Investigators. Novel concept to guide systolic heart failure medication by repeated biomarker testing-results from TIME-CHF in context of predictive, preventive, and personalized medicine. EPMA J 2018 Jun;9(2):161-173 [FREE Full text] [doi: 10.1007/s13167-018-0137-7] [Medline: 29896315] 
44. del Valle KL, McDonnell ME. Chronic care management services for complex diabetes management: a practical overview. Curr Diab Rep 2018 Oct 20;18(12):135. [doi: 10.1007/s11892-018-1118-x] [Medline: 30343337]

\author{
Abbreviations \\ ACEI: angiotensin-converting enzyme inhibitor \\ ARB: angiotensin receptor blocker \\ BP: blood pressure \\ CMS: Centers for Medicare and Medicaid Services \\ COPD: chronic obstructive pulmonary disease \\ DM: diabetes mellitus \\ EHR: electronic health record \\ HF: heart failure \\ PCI: percutaneous coronary intervention \\ PRO: patient-reported outcome \\ QI: quality improvement
}

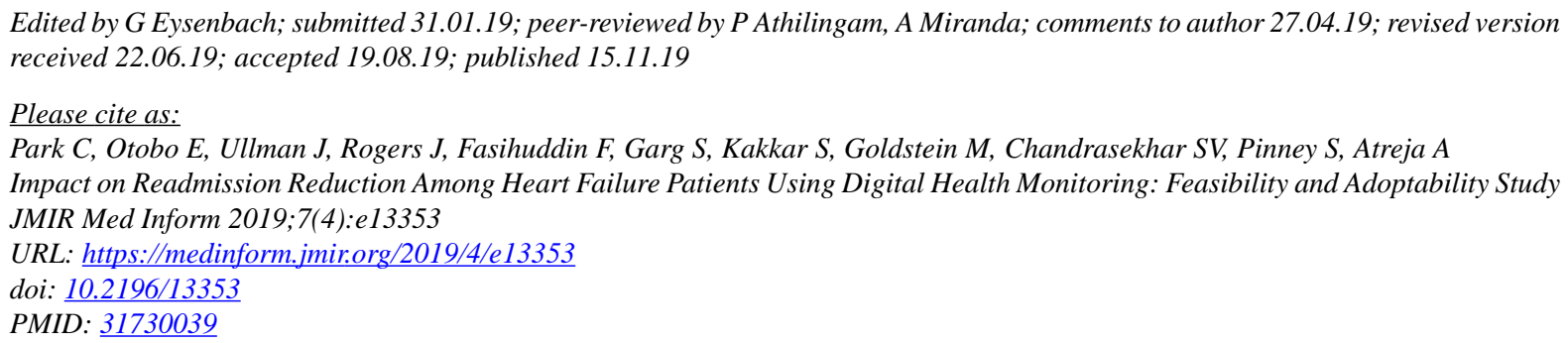

(C) Christopher Park, Emamuzo Otobo, Jennifer Ullman, Jason Rogers, Farah Fasihuddin, Shashank Garg, Sarthak Kakkar, Marni Goldstein, Sai Vishudhi Chandrasekhar, Sean Pinney, Ashish Atreja. Originally published in JMIR Medical Informatics (http://medinform.jmir.org), 15.11.2019. This is an open-access article distributed under the terms of the Creative Commons Attribution License (https://creativecommons.org/licenses/by/4.0/), which permits unrestricted use, distribution, and reproduction in any medium, provided the original work, first published in JMIR Medical Informatics, is properly cited. The complete bibliographic information, a link to the original publication on http://medinform.jmir.org/, as well as this copyright and license information must be included. 